\title{
RETRACTED ARTICLE: Evolution and fate of chemical elements in the Earth's crust, ocean, and atmosphere
}

\author{
Alberto Carpinteri · Amedeo Manuello
}

Received: 24 January 2014/ Accepted: 14 June 2014/Published online: 20 July 2014

(C) Springer Science+Business Media Dordrecht 2014

This article has been withdrawn by the Publisher and the Society in agreement with the Editor-in-Chief due to conflict of interest reasons. In a commitment to scientific integrity we decided to withdraw the article as the editorial process had been compromised.

\footnotetext{
A. Carpinteri · A. Manuello ( $₫)$

Department of Structural, Geotechnical and Building Engineering, Politenico di Torino, Corso Duca degli

Abruzzi, 24, 10129 Turin, Italy

e-mail: amedeo.manuellobertetto@polito.it
} 